\title{
Lymphadenopathy: Differentiation between Tuberculosis and Other Non-Tuberculosis Causes like Follicular Lymphoma
}

\author{
Karan Thakkar*, Saket Mukund Ghaisas and Manmohan Singh \\ Pfizer, Mumbai, India
}

Keywords: CD20, acid fast bacilli, Koch's disease, extrapulmonary tuberculosis, splenomegaly, lymphoma, lymphadenitis, GeneXpert

\section{INTRODUCTION}

Lymphadenopathy (LD) is a common clinical presentation in outpatient departments (1-3). It is a cause of concern for the patient and physician alike even in the absence of symptoms (4). In India and some other developing countries, tuberculosis (TB) is the first differential diagnosis for a patient who presents with chronic lymph node enlargement (4-6). Nonetheless, studies have shown that more than $50 \%$ of cases of LD are due to non-TB causes and, in these cases, excision biopsy (EB) with histopathology and/or microbiological examination, is the only way to exclude TB $(2,5,7)$. Malignancies may account for about $1 \%$ of cases of LD (1). The causes of LD can be broadly classified as shown below $(8-10)$ :

Edited by: Joav Merrick,

Ministry of Social Affairs, Israel

Reviewed by:

Keyue Ding,

Queen's University, Canada Mohammed Morad,

Clalit Health Services, Israel

*Correspondence:

Karan Thakkar

karan_thkkr@hotmail.com

Specialty section: This article was submitted to Family Medicine and Primary Care, a section of the journal

Frontiers in Public Health

Received: 20 December 2015 Accepted: 12 February 2016

Published: 25 February 2016

Citation:

Thakkar K, Ghaisas SM and Singh M (2016) Lymphadenopathy:

Differentiation between Tuberculosis and Other Non-Tuberculosis Causes like Follicular Lymphoma. Front. Public Health 4:31. doi: 10.3389/fpubh.2016.00031
1. Malignancy: lymphoma, acute lymphoblastic leukemia, acute promyelocytic leukemia, and metastasis.

2. Infection: TB, streptococcal infection, pediculosis, measles, chickenpox, infectious mononucleosis, HIV, toxoplasmosis, and Taenia.

3. Autoimmune: systemic lupus erythematosus, serum sickness, juvenile idiopathic arthritis, and rheumatoid arthritis.

4. Drugs: phenytoin, cotrimoxazole, allopurinol, atenolol, penicillins, etc.

5. Miscellaneous: sarcoidosis, storage disorders, histiocytosis, cystic fibrosis, and hypothyroidism.

Of the various causes in adults, lymphoma and HIV infection should be ruled out in inconclusive cases (5). A retrospective analysis of 5 months data from a South African Lymphoma Clinic showed that out of 21 patients of lymphoma, 18 were mistakenly diagnosed as TB in the 12 months preceding the histological confirmation of lymphoma (11). Of the different types of lymphomas, the most common is "diffuse large B cell lymphoma" followed by "follicular lymphoma" (FL) (12, 13). FL is the most common indolent lymphoma (14). An early diagnosis of FL has become important in the light of availability of treatment options that can delay disease progression. LD due to FL and TB has a lot of similarities and differences. The article describes them with the objective of creating more awareness about FL enabling its early diagnosis. The presenting symptoms of FL are subtle, if any, and hence can be missed easily until disease progression to a more aggressive form (15-17).

\section{LYMPHADENOPATHY: TB AND FL - SIMILARITIES $(14,18)$}

1. Classically, TB LD has been described as multiple, matted, hard to fluctuant with draining sinuses. But in stages 1 and 2, lymph nodes may be discrete, firm, and rubbery just like FL LD (19). 
2. Commonly involved lymph node regions in both $(2,7,16,17$, 20, 21): cervical, axillary, and inguinal lymph nodes.

3. Both may have a non-specific presentation (9): fatigue, low grade fever, night sweats, weight loss, etc.

4. Fine needle aspiration cytology (FNAC): both TB and FL LD may show evidence of granulomatous inflammation (5).

\section{LYMPHADENOPATHY: CLUES INDICATING NON-TB ETIOLOGY $(14,17,18,20,22)$}

1. Age more than $40-50$ years, since most cases of TB LD occur in 20-40 years age group.

2. Supraclavicular LD may point toward a malignancy (8).

3. No history of exposure to a case of TB.

4. An inconclusive repeat FNAC.

5. Normal tuberculin skin test (TST).

6. Lack of resolution of clinical symptoms and regression of LD after starting anti-TB therapy (ATT). In most cases of non-resistant TB LD, lymph node regression occurs within 2-4 months of start of ATT (23-25). Lack of response after 2 months of starting therapy should lead to consideration of resistance or non-TB causes.

A general diagnostic algorithm in a case of chronic LD is presented in Figure 1.

\section{CHRONIC LD: SUGGESTED INITIAL WORKUP}

1.Complete blood counts, erythrocyte sedimentation rate, and a careful evaluation of the peripheral blood smear. $(5,15,22,26)$.

2. Tests such as serum lactate dehydrogenase, uric acid, and beta-2-microglobulin are good indicators of a lymphomatous process.

3. TST.

4. A chest $\mathrm{X}$-ray may indicate mediastinal enlargement in case of FL or lesions of pulmonary TB.

5. Abdominal USG is an important non-invasive investigation in suspicious cases, since $50 \%$ of FL patients may have splenomegaly (26). Especially, if splenomegaly is massive, some of the differential diagnosis are chronic lymphocytic leukemia, non-Hodgkin lymphoma, chronic myelocytic leukemia, polycythemia vera, myelofibrosis with myeloid metaplasia, or hairy cell leukemia $(27,28)$. Splenic involvement in TB usually occurs in the military form and is very rare $(29,30)$.

Lymph node aspirate/biopsy for microscopy/histopathology and culture. Atypical lymphoid hyperplasia should be considered non-diagnostic rather than negative for a malignancy. Careful follow-up and an additional lymph node biopsy must be strongly considered in such cases (31). Fine needle aspiration (FNA) is an

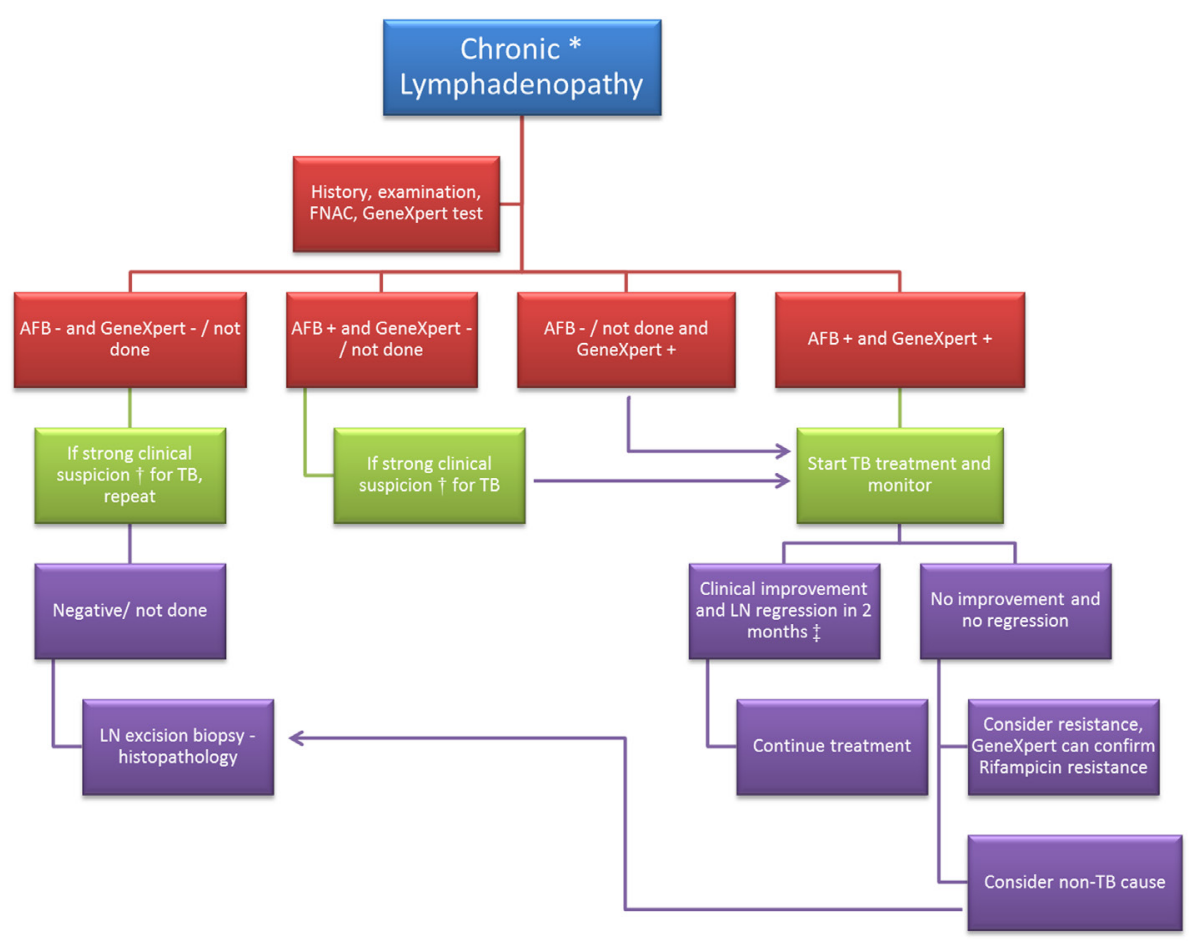

FIGURE 1 | Diagnostic algorithm in a case of chronic lymphadenopathy. FNAC, fine needle aspiration cytology; AFB, acid fast bacilli; "_", negative; "+”, positive; LN, lymph node. *Chronic lymphadenopathy: lymphadenopathy due to unexplained causes and duration $\geq 2$ weeks. ${ }^{\dagger} \mathrm{Clinical}$ suspicion of tuberculosis (TB) would be based on (1) past history of TB or exposure to a case of TB; (2) age <50 years; (3) typical features of TB lymph node - multiple, matted, hard to fluctuant with draining sinuses; (4) symptoms like - fatigue, low grade fever, night sweats, weight loss, etc. *Based on studies conducted on response to treatment in cases of TB lymphadenopathy (23-25). 
established investigation in the diagnosis of tuberculous lymphadenitis as it is a simple and relatively painless procedure (32-35). EB provides more information about histological architecture but requires surgical and anesthetic facilities and may leave a scar. The sensitivity of FNA and EB must be looked at in context of the combination diagnostic modality used. For example, for diagnosis of TB LAD, the sensitivity $(95 \% \mathrm{CI})$ of FNA + cytological assessment is $38.5 \%$ (20-59\%), FNA + microscopy for acid fast bacilli (AFB) is $18.2 \%$ (5-40\%), and FNA + culture is $86.4 \%$ (65-97\%), whereas that for $\mathrm{EB}+$ histological assessment is $95.8 \%$ (88-100\%) and EB + microscopy for AFB is $16.7 \%$ (2-32\%) (33). A study conducted by Singh et al. showed that EB was about twice as sensitive as FNA examination $(p<0.05)$ using the conventional diagnostic criteria of histology and culture for TB LAD (36). The same study also showed that, the positivity of polymerase chain reaction (PCR) in TB LAD cases using material from FNA and EB was same (10 out 22 cases of TB LAD) but by increasing the quantity of the clinical specimen for PCR analyses, more number of cases were diagnosed by EB (15/22) compared to FNA (12/22) (36). Thus, PCR on FNA samples can be performed as an initial test and EB histology and PCR should be recommended in cases negative on FNA + PCR, or if there is clinical suspicion for non-TB cases (36-38). For diagnosing lymphoma, although EB is an accepted "gold standard," a core needle biopsy is also a viable alternative, provided that the number and size of cores for morphologic analysis are not compromised (39). GeneXpert test of lymph node biopsy material (40-42). It is a semiautomated and rapid method based on the detection of DNA of Mycobacterium tuberculosis and mutations responsible for rifampicin resistance (43). This method has been endorsed by the World Health Organization for rapid diagnosis of TB (44). Its utility is known for diagnosis of both pulmonary and extrapulmonary TB. According to a systematic review by Smith et al., GeneXpert test is likely to be of greatest utility when testing lymph node or tissue samples (besides CSF), and differentiating tuberculous from non-tuberculous mycobacteria in smear positive samples (43). A study has reported that the GeneXpert test reduced the time to begin ATT by 4 weeks in both pulmonary and extrapulmonary TB cases with a negative sputum AFB smear (45). The positive

\section{REFERENCES}

1. Bazemore AW, Smucker DR. Lymphadenopathy and malignancy. Am Fam Physician (2002) 66:2103-10.

2. Biswas G, Das A, Haldar D, Mukherjee A, Dutta S, Sinha R. Clinicopathological correlates of cervical lymphadenopathy: a hospital based study. Indian J Otolaryngol Head Neck Surg (2013) 65:42-7. doi:10.1007/ s12070-011-0443-Z

3. Chamyal PC, Sabarigirish K. Clinico-pathological correlation study of cervical lymph node masses. Indian J Otolaryngol Head Neck Surg (1997) 49:402-5. doi:10.1007/BF02994662

4. Mohseni S, Shojaiefard A, Khorgami Z, Alinejad S, Ghorbani A, Ghafouri A. Peripheral lymphadenopathy: approach and diagnostic tools. Iran J Med Sci (2014) 39:158-70.

5. Pandit S, Choudhury S, Das A, Das SK, Bhattacharya S. Cervical lymphadenopathy - pitfalls of blind antitubercular treatment. J Health Popul Nutr (2014) 32:155-9.

6. Prasad RR, Narasimhan R, Sankaran V, Veliath AJ. Fine-needle aspiration cytology in the diagnosis of superficial lymphadenopathy: an and negative predictive values of this test are $90-100$ and $70-85 \%$, respectively, since it has a specificity of almost $98-100 \%$ (42, 46-48). A negative test may not necessarily rule out TB but a positive test indicates TB; and hence, it has been described as a "rule-in" test. There are concerns about affordability but costs are being brought down followed by increased demand, support from health authorities, and public-private partnership $(49,50)$.

\section{CONCLUSION}

Though FL is one of the less common causes of LD, there should be a high index of suspicion in selected cases to enable an early diagnosis. Key factors that would point toward a non-TB cause of LD are age $>40$ years, no history of TB, normal TST, inconclusive FNAC, negative GeneXpert test, and non-resolution of clinical symptoms and/or regression of LD in 2-4 months after starting ATT. An early diagnosis could permit the use of drugs, which have been shown to delay progression of FL.

\section{AUTHOR CONTRIBUTIONS}

KT, SG, and MS: contributed substantially to the conception of the work and interpretation of data for the work; involved in drafting the work and revising it critically for important intellectual content; approved the final version to be published; agreed to be accountable for all aspects of the work in ensuring that questions related to the accuracy or integrity of any part of the work are appropriately investigated and resolved.

\section{ACKNOWLEDGMENTS}

We would like to thank Dr. Durga Gadgil, Dr. Agnieszka Zareba, and Lisa Melia for their support and guidance.

\section{FUNDING}

The article processing fees have been sponsored by the Regional Medical Monitoring Organization, Pfizer (India).

analysis of 2,418 cases. Diagn Cytopathol (1996) 15:382-6. doi:10.1002/ (SICI)1097-0339(199612)15:5<382::AID-DC5>3.0.CO;2-E

7. Sharma SK, Mohan A. Extrapulmonary tuberculosis. Indian J Med Res (2004) 120:316-53.

8. Ferrer R. Lymphadenopathy: differential diagnosis and evaluation. Am Fam Physician (1998) 58:1313-20.

9. Habermann TM, Steensma DP. Lymphadenopathy. Mayo Clin Proc (2000) 75:723-32. doi:10.4065/75.7.723

10. Pangalis GA, Vassilakopoulos TP, Boussiotis VA, Fessas P. Clinical approach to lymphadenopathy. Semin Oncol (1993) 20:570-82.

11. Puvaneswaran B, Shoba B. Misdiagnosis of tuberculosis in patients with lymphoma. S Afr Med J (2012) 103:32-3. doi:10.7196/samj.6093

12. Mondal SK, Mandal PK, Samanta TK, Chakaborty S, Roy SD, Roy S. Malignant lymphoma in eastern India: a retrospective analysis of 455 cases according to World Health Organization classification. Indian J Med Paediatr Oncol (2013) 34:242-6. doi:10.4103/0971-5851.125235

13. Naresh KN, Srinivas V, Soman CS. Distribution of various subtypes of nonHodgkin'slymphoma in India: a study of 2773 lymphomas using R.E.A.L. and WHO classifications. Ann Oncol (2000) 11(Suppl 1):63-7. doi:10.1023/A:1011103326656 
14. Longo D. 18th ed. In: Longo DL, Fauci AS, Kasper DL, Hauser SL, Jameson JL, Loscalzo J, editors. Malignancies of lymphoid cells. In: Follicular Lymphoma. New York: The McGraw-Hill Companies (2012).

15. Freedman A. Follicular lymphoma: 2014 update on diagnosis and management. Am J Hematol (2014) 89:429-36. doi:10.1002/ajh.23674

16. O'Connor OA, Vose JM. Indolent follicular lymphoma. Lymphoma Res Found (2008).

17. Salles GA. Clinical features, prognosis and treatment of follicular lymphoma. Hematology Am Soc Hematol Educ Program (2007) 2007:216-25. doi:10.1182/ asheducation-2007.1.216

18. Raviglione MC, O'Brien RJ. 18th ed. In: Longo DL, Fauci AS, Kasper DL, Hauser SL, Jameson JL, Loscalzo J, editors. Tuberculosis. In: Lymph Node TB (Tuberculous Lymphadenitis). New York: The McGraw-Hill Companies (2012).

19. Jones PG, Campbell PE. Tuberculous lymphadenitis in childhood: the significance of anonymous mycobacteria. Br J Surg (1962) 50:302-14. doi:10.1002/ bjs. 18005022112

20. Luminari S, Bellei M, Biasoli I, Federico M. Follicular lymphoma. Rev Bras Hematol Hemoter (2011) 34:54-9. doi:10.5581/1516-8484.20120015

21. Neelakantan S, Nair PP, Emmanuel RV, Agrawal K. Diversities in presentations of extrapulmonary tuberculosis. BMJ (2013) 2013:bcr2013008597. doi:10.1136/bcr-2013-008597

22. Mohapatra PR, Janmeja AK. Tuberculous lymphadenitis. J Assoc Physicians India (2009) 57:585-90.

23. Jain N, Bajpai A, Jain S. Outcomes of category III and I in immunocompetent patients of tuberculous lymphadenopathy treated in revised national tuberculosis control programme. Lung India (2010) 27:115. doi:10.4103/0970-2113.68305

24. Jha BC, Dass A, Nagarkar NM, Gupta R, Singhal S. Cervical tuberculous lymphadenopathy: changing clinical pattern and concepts in management. Postgrad Med J (2001) 77:185-7. doi:10.1136/pmj.77.905.185

25. Kandala V, Kondapalli N, Kalagani Y, Kandala M. Directly observed treatment short course in immunocompetent patients of tuberculous cervical lymphadenopathy treated in revised national tuberculosis control programme. Lung India (2012) 29:109. doi:10.4103/0970-2113.95300

26. Freytes CO, Merten JA. Follicular lymphoma - clinical evaluation. Medscape Ref Drugs Dis Proced (2015). Available from: http://emedicine.medscape.com/ article/203268-overview\#a4

27. Saboo SS, Krajewski KM, O’Regan KN, Giardino A, Brown JR, Ramaiya N, et al. Spleen in haematological malignancies: spectrum of imaging findings. Br J Radiol (2012) 85:81-92. doi:10.1259/bjr/31542964

28. Zaarour M, Weerasinghe C, Moussaly E, Hussein S, Atallah J-P. “The great mimicker": an unusual etiology of cytopenia, diffuse lymphadenopathy, and massive splenomegaly. Case Rep Med (2015) 2015:637965. doi:10.1155/2015/637965

29. Basa JV, Singh L, Jaoude WA, Sugiyama G. A case of isolated splenic tuberculosis. Int J Surg Case Rep (2015) 8C:117-9. doi:10.1016/j.ijscr.2014.10.050

30. Topal U, Savci G, Yurtkuran Sadikoglu M, Parlak M, Tuncel E. Splenic involvement of tuberculosis: US and CT findings. Eur Radiol (1994) 4:577-9. doi:10.1007/BF00226834

31. Assessment of Lymphadenopathy. BMJ Best Pract (2014). Available from: http://bestpractice.bmj.com.proxyl.athensams.net/bestpractice/

32. Fontanilla J-M, Barnes A, von Reyn CF. Current diagnosis and management of peripheral tuberculous lymphadenitis. Clin Infect Dis (2011) 53:555-62. doi:10.1093/cid/cir454

33. Knox J, Lane G, Wong JSJ, Trevan PG, Karunajeewa H. Diagnosis of tuberculous lymphadenitis using fine needle aspiration biopsy. Intern Med J (2012) 42:1029-36. doi:10.1111/j.1445-5994.2012.02748.x

34. van Loenhout-Rooyackers JH, Richter C. Diagnosis and treatment of tuberculous lymphadenitis of the neck. Ned Tijdschr Geneeskd (2000) 144:2243-7.

35. Polesky A, Grove W, Bhatia G. Peripheral tuberculous lymphadenitis: epidemiology, diagnosis, treatment, and outcome. Medicine (Baltimore) (2005) 84:350-62. doi:10.1097/01.md.0000189090.52626.7a

36. Singh KK, Muralidhar M, Kumar A, Chattopadhyaya TK, Kapila K, Singh MK, et al. Comparison of in house polymerase chain reaction with conventional techniques for the detection of Mycobacterium tuberculosis DNA in granulomatous lymphadenopathy. J Clin Pathol (2000) 53:355-61. doi:10.1136/jcp.53.5.355
37. Baek CH, Kim SI, Ko YH, Chu KC. Polymerase chain reaction detection of Mycobacterium tuberculosis from fine-needle aspirate for the diagnosis of cervical tuberculous lymphadenitis. Laryngoscope (2000) 110:30-4. doi:10.1097/00005537-200001000-00006

38. Ikram A, Ahmed SA, Khan FA, Khadim MT, Satti L. Rapid Mycobacterium tuberculosis DNA detection on fine needle aspirates from extra pulmonary lymph nodes. JColl Physicians Surg Pak (2015) 25:417-21. doi:06.2015/ JCPSP. 417421

39. Amador-Ortiz C, Chen L, Hassan A, Frater JL, Burack R, Nguyen TT, et al. Combined core needle biopsy and fine-needle aspiration with ancillary studies correlate highly with traditional techniques in the diagnosis of nodal-based lymphoma. Am J Clin Pathol (2011) 135:516-24. doi:10.1309/ AJCP3WZ8ZDRJQDOU

40. Niemz A, Boyle DS. Nucleic acid testing for tuberculosis at the point-ofcare in high-burden countries. Expert Rev Mol Diagn (2012) 12:687-701. doi:10.1586/erm.12.71

41. Small PM, Pai M. Tuberculosis diagnosis - time for a game change. $N$ Engl J Med (2010) 363:1070-1. doi:10.1056/NEJMe1008496

42. Zeka AN, Tasbakan S, Cavusoglu C. Evaluation of the GeneXpert MTB/RIF assay for rapid diagnosis of tuberculosis and detection of rifampin resistance in pulmonary and extrapulmonary specimens. JClin Microbiol (2011) 49:4138-41. doi:10.1128/JCM.05434-11

43. Maynard-Smith L, Larke N, Peters JA, Lawn SD. Diagnostic accuracy of the Xpert MTB/RIF assay for extrapulmonary and pulmonary tuberculosis when testing non-respiratory samples: a systematic review. BMC Infect Dis (2014) 14:709. doi:10.1186/s12879-014-0709-7

44. World Health Organization. WHO Endorses New Rapid Tuberculosis Test (2010). Available from: http://www.who.int/mediacentre/news/releases/2010/ tb_test_20101208/en/

45. Omrani AS, Al-Otaibi MF, Al-Ateah SM, Al-Onazi FM, Baig K, El-Khizzi NA, et al. GeneXpert MTB/RIF testing in the management of patients with active tuberculosis; a real life experience from Saudi Arabia. Infect Chemother (2014) 46:30-4. doi:10.3947/ic.2014.46.1.30

46. Denkinger CM, Schumacher SG, Boehme CC, Dendukuri N, Pai M, Steingart KR. Xpert MTB/RIF assay for the diagnosis of extrapulmonary tuberculosis: a systematic review and meta-analysis. Eur Respir J (2014) 44:435-46. doi:10.1183/09031936.00007814

47. Tadesse M, Abebe G, Abdissa K, Aragaw D, Abdella K, Bekele A, et al. GeneXpert MTB/RIF assay for the diagnosis of tuberculous lymphadenitis on concentrated fine needle aspirates in high tuberculosis burden settings. PLoS One (2015) 10:e0137471. doi:10.1371/journal.pone.0137471

48. Walusimbi S, Bwanga F, De Costa A, Haile M, Joloba M, Hoffner S. Metaanalysis to compare the accuracy of GeneXpert, MODS and the WHO 2007 algorithm for diagnosis of smear-negative pulmonary tuberculosis. $B M C$ Infect Dis (2013) 13:507. doi:10.1186/1471-2334-13-507

49. Prasad R. WHO-Approved TB Test, Now at a Subsidised Price. The Hindu (2013) Available from: http://www.thehindu.com/sci-tech/health/whoapproved-tb-test-now-at-a-subsidised-price/article4554843.ece

50. The Bill and Melinda Gates Foundation. Public-Private Partnership Announces Immediate 40 Percent Cost Reduction for Rapid TB Test. Bill Melinda Gates Found (2012). Available from: http://www.gatesfoundation.org/MediaCenter/Press-Releases/2012/08/PublicPrivate-Partnership-AnnouncesImmediate-40-Percent-Cost-Reduction-for-Rapid-TB-Test

Conflict of Interest Statement: The authors are employees of Pfizer (India). Dr. KT is currently working as a Regional Medical Monitor on a Pfizer sponsored clinical trial on follicular lymphoma. Authors have prepared this article based on a literature review and the article does not include any official company stand/ declaration or any Pfizer sponsored clinical trial data.

Copyright (c) 2016 Thakkar, Ghaisas and Singh. This is an open-access article distributed under the terms of the Creative Commons Attribution License (CC BY). The use, distribution or reproduction in other forums is permitted, provided the original author(s) or licensor are credited and that the original publication in this journal is cited, in accordance with accepted academic practice. No use, distribution or reproduction is permitted which does not comply with these terms. 